\title{
Magnetotelluric investigation in the High Agri Valley (southern Apennine, Italy)
}

\author{
M. Balasco ${ }^{1}$, A. Giocoli ${ }^{1,2}$, S. Piscitelli ${ }^{1}$, G. Romano ${ }^{3}$, A. Siniscalchi ${ }^{3}$, T. A. Stabile ${ }^{1}$, and S. Tripaldi ${ }^{3}$ \\ ${ }^{1}$ IMAA, Istituto di Metodologie per l'Analisi Ambientale, CNR, C.da S. Loja, Z.I., 85050, Tito Scalo (PZ), Italy \\ ${ }^{2}$ ENEA, Rome, Italy \\ ${ }^{3}$ Dipartimento di Scienze della Terra e Geoambientali, Università di Bari, Campus Universitario, Via Orabona 4, \\ 70125 Bari, Tito Scalo (PZ), Italy
}

Correspondence to: M. Balasco (marianna.balasco@imaa.cnr.it)

Received: 10 July 2014 - Published in Nat. Hazards Earth Syst. Sci. Discuss.: 4 November 2014

Revised: - - Accepted: 8 March 2015 - Published: 13 April 2015

\begin{abstract}
In this paper we present the result of a magnetotelluric (MT) investigation carried out across the High Agri Valley (HAV), southern Italy. Several MT soundings were carried out in order to obtain a $\sim 15 \mathrm{~km}$ long 2-D resistivity model with an investigation depth of $\sim 10 \mathrm{~km}$. The main aim was to provide valuable data on the geological and structural setting of the HAV. The MT model was compared with preexisting geological, geophysical and seismic data. The MT model can be schematized as a superposition of three stack lateral varying layers with different thickness and resistivity values: a surficial low-medium resistivity layer associated with the Quaternary deposits and to the allochthonous units; and a deeper high resistivity layer related to the Apulia Platform, separated by a thin layer connected to the mélange zone and to the Pliocene terrigenous marine deposits. Sharp lateral resistivity variations are interpreted as faults that, on the basis of accurate focal mechanism computations, display normal-faulting kinematics.
\end{abstract}

\section{Introduction}

The High Agri Valley (HAV, Basilicata region, southern Italy) is an intermontane basin of the southern Apennine chain characterized by complex geological setting and by active tectonics, as testified by one of the most destructive earthquakes in this area, the M7.0 1857 Basilicata earthquake (Fig. 1). Furthermore, in the last years it has been exposed to intense hydrocarbon exploration and extraction, representing the largest onshore Western European oil field.
Although a huge amount of geophysical data were collected in the area, a discrepancy has to be reported between the availability of information related to the shallow geological structures and to the deeper ones. The surficial geological and structural setting (up to few hundred metres of depth) is in fact well described in several geological and geophysical studies (Giano et al., 2000a; Cello et al., 2003; Colella et al., 2004; Morandi and Ceragioli, 2002, Rizzo et al., 2004), while information on the deep structure of the valley, where the oil reservoirs are located, is generally kept confidential.

Among the few papers dealing with the deep structure of the HAV, it is worth mentioning Nicolai and Gambini (2007) and Valoroso et al. (2011). The first paper shows the regional structural setting as inferred by industry seismic profiles and oil wells; the second one presents the results of a local earthquake tomography related to the 3-D $\mathrm{Vp}$ and $\mathrm{Vp} / \mathrm{Vs}$ distribution of the HAV. Additional information can be retrieved in Dell'Aversana (2003). This work, even if it is missing of crucial information like the exact location of the survey, shows (even though with low-resolution images) the result of a magnetotelluric (MT) investigation performed by an oil company along a profile crossing the HAV.

Generally, MT investigations can play a key role in the study of geological and structural setting by furnishing complementary results of seismic exploration, especially in such geologically complex areas where the quality of standard seismic is often poor. The MT technique permits us to obtain the distribution of the electrical resistivity from the subsurface up to seismogenic depth, avoiding the technical problems and high cost of generating artificial seismic signals. 
Furthermore, the electrical resistivity is correlated with the major geological units and, in particular, is dominated by their porosity and the contained fluids. Such MT method peculiarity has been proven in a broad range of applications regarding the studies of the Earth's interior, playing a crucial role in the characterization of faulted areas both in volcanic (Di Maio et al., 1998; Siniscalchi et al., 2012) and seismic environments (Tank et al., 2005; Bedrosian, 2007; Diaferia et al., 2008; Balasco et al., 2011; Becken and Ritter, 2012; Gabàs et al., 2014).

In this paper we present the result of a MT investigation in order to give further information helpful to understanding the geological and structural setting of the HAV. The obtained MT model was compared with seismic tomographies conducted in the study area (Valoroso et al., 2009, 2011), with deep geological sections proposed by several authors (Mazzoli et al., 2001; Borraccini et al., 2002; Shiner et al., 2004) and with the seismicity recorded by a local seismic network from January 2002 to December 2012. The interpretation of the MT model can resolve some outstanding issues, like the depth of the bedrock below the Quaternary deposits and the deep geometrical characterization of the faults.

\section{Geological framework}

The High Agri Valley is a NW-SE trending intermontane basin formed during the Quaternary period along the axial zone of the Southern Apennines thrust belt chain (Fig. 1a). This basin is $\sim 30 \mathrm{~km}$ long and $12 \mathrm{~km}$ wide and is filled with Quaternary continental deposits which cover downthrown pre-Quaternary substratum of the Apennines Chain. The Quaternary deposits (QD) are essentially Lower-Middle Pleistocene talus breccia (Brecce di Marsico, Di Niro and Giano, 1995), Middle-Upper Pleistocene alluvial-lacustrine sediments (Complesso Val d'Agri, Di Niro et al., 1992) and Upper Pleistocene-Holocene alluvial deposits. The preQuaternary substratum of the HAV consists of allochthonous units on the 6-7 km thick Mesozoic-Tertiary carbonate sequence of the Apulia Carbonate Platform (AP), which is stratigraphically overlain by Pliocene terrigenous marine deposits (TM). The allochthonous units are comprised of the Mesozoic-Cenozoic shallow-water and slope carbonates (Campania-Lucania Platform), mainly outcropping along the western side of the basin, and of the coeval pelagic successions (Lagonegro units, LU; Scandone, 1967) and their Tertiary siliciclastic sediments (e.g. Gorgoglione Flysch, Albidona Formation). Rocks of the LU crop out mainly along the eastern flank of the valley and in sparse tectonic windows beneath the Monti della Maddalena thrust sheet on the western side. Geophysical investigation and deep well logs show that in HAV the top of the AP is between 2 and $4 \mathrm{~km}$ below sea level (Dell'Aversana, 2003) (Fig. 1b). Effective decoupling between the allochthon and the buried AP is related to the rheological contrast produced by a mélange zone
(M), which is generally several hundreds of metres thick and locally exceeding $1 \mathrm{~km}$ in thickness (Fig. 1b) (Mazzoli et al., 2001; Shiner et al., 2004).

Brittle tectonics have strongly controlled the formation and evolution of the HAV. The deformation is testified by seismic activity and by loose slope deposits and paleosols involved in faulting in the last $40 \mathrm{kyr}$ (Giano et al., 2000a, b; D'Addezio et al., 2006). The HAV was hit by the M7.0 1857 Basilicata earthquake (Branno et al., 1985), whose macroseismic field covered a wide sector of the Southern Apennines chain. So far, conflicting seismogenic models for the HAV are discussed in the recent literature. In particular, the seismogenic fault system capable of producing large events is alternatively associated with (1) the Eastern Agri Fault System (EAFS), a NW-trending, SW-dipping normal-fault system bounding the eastern side of the basin and characterized by a mature geomorphic expression (Benedetti et al., 1998; Cello and Mazzoli, 1999; Michetti et al., 2000; Cello et al., 2000, 2003; Giano et al., 2000a, b; Barchi et al., 2007); and (2) the Monti della Maddalena Fault System (MMFS), a NW-trending, NE-dipping normal-fault system cross-cutting the mountain range to the west and characterized by a subtle geomorphic expression (Pantosti and Valensise, 1990; Maschio et al., 2005; Burrato and Valensise, 2007; Improta et al., 2010). In addition, Borraccini et al. (2002) propose a decoupling among most of the surface faults, which appear rooted within the M, and deeper faults in AP. Thus, they supposed that the most probable deep structure responsible for the development of the active fault system in HAV is a NWstriking and SW-dipping fault buried in the AP just below the central part of the valley floor.

\section{Magnetotelluric data}

In September 2007 a broad-band MT investigation, consisting of 12 soundings, was collected using $24 \mathrm{bit} \mathrm{A} / \mathrm{D}$ acquisition systems (MT24LF, EMI-Schlumberger). The soundings were aligned along a $15 \mathrm{~km}$ long NE-SW profile, which extends approximately from Magorno to Viggiano, crossing whole HAV (Fig. 1). Taking into account the strike of the regional geological brittle structures, the $x$ component of electric and magnetic fields was collected in the $135^{\circ} \mathrm{N}$ direction, whereas the $y$ component was oriented along the $45^{\circ} \mathrm{N}$ direction. The electrical configuration and electrode lines were based on the availability of space, preferring a "double L" configuration in which two electric dipoles were laid end to end in the SW-NE or NW-SE directions. The presence of surficial and very small-scale conductivity anomalies (respect of skin depth of the electromagnetic waves) can cause a shift between the two components of the apparent resistivity curves. When a very small inhomogeneous body is localized just below the sounding, the static shift might affect only one of the two double components. The "double L" configuration of the electric lines allows us to obtain a simultaneous acqui- 


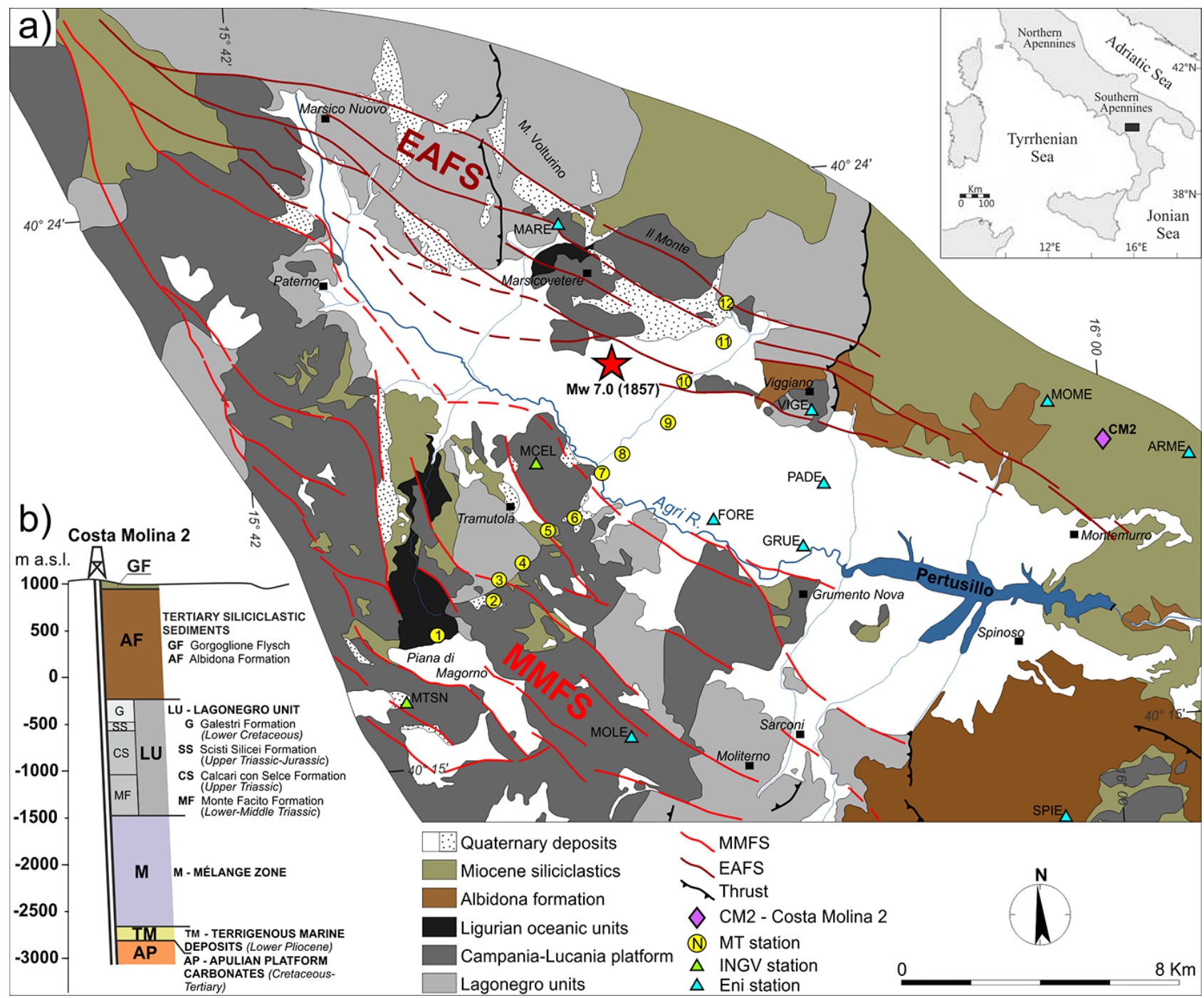

Figure 1. (a) Morphostructural map of the High Agri Valley (HAV) showing the main Quaternary fault systems and the location of the magnetotelluric soundings (modified from Giocoli et al., 2015). (b) Stratigraphic log of the Costa Molina 2 well (modified from Stabile et al., 2014b).

sition of two adjoining soundings (two soundings along the $x y$ or the $y x$ direction, depending on the availability of space at the several sites). It could be possible to recognize and partially remove these effects by comparing two adjoining soundings; in fact, in the same site and along the same components, no very large changes on the shape of the curves are expected (Bedrosian et al., 2004).

The electric field $(E)$ was measured by recording the voltage variation versus time between a pair of grounded $\mathrm{Pb} / \mathrm{PbCl}_{2}$ unpolarizable electrodes, distant maximum $100 \mathrm{~m}$ apart. The magnetic field was collected by induction coils able to detect the electromagnetic natural field $(H)$ in the $0.0001-1000 \mathrm{~Hz}$ frequency range. At each sounding the electric $\left(E_{x}, E_{y}\right)$ and magnetic components $\left(H_{x}, H_{y}\right)$ were recorded. The data acquired were generally of good quality; when necessary after a visual inspection, the bad data were removed from the time series.

The sampling frequency of data recording was set to $6.25 \mathrm{~Hz}$ (low frequency, LF) and to $500 \mathrm{~Hz}$ (high frequency, $\mathrm{HF}$ ). The acquisitions length (at least 24 and $2 \mathrm{~h}$ respectively for LF and HF events) was chosen in order to obtain reliable stability of the measures (Balasco et al., 2004). Furthermore, to avoid cultural noise, HF events were launched during night-time.

Time series data were analyzed using the robust processing code of Egbert (1997) to compute the MT transfer function. From the acquired time series, divided into short time windows and Fourier transformed, the apparent resistivity and phase were obtained in the period range 0.01-240 s.

Considering the relative small spacing among the stations $(\sim 1 \mathrm{~km})$, strong variations between neighbourhood sites and 
long-period data are unexpected unless distortion or galvanic effects take place. Galvanic effects (also known as "static shift" effects) can be easily recognized, whereas long-period phase curves do not change significantly from site to site, but strong and broad period range resistivity variations are observed. Before inverting the MT data, the possible presence of static shift was discriminated and resolved by comparing (i) for each site the two sets of MT curves resulting from the "double L" acquisition configuration and (ii) resistivity and phase curves related to neighbourhood sites.

As mentioned before, the data presented in this work have been acquired along a transect crossing the main geological features of the HAV $(\sim \mathrm{N} 120-\mathrm{N} 150)$. The choice to record the magnetic and the electric fields along directions different from the common ones $(\mathrm{N}-\mathrm{S}$ and $\mathrm{E}-\mathrm{W})$ was made in order to limit the data manipulation necessary to perform the inversion of the data as much as possible. Excluding the application of a 1-D inversion scheme, it is necessary (i) to assess whether or not a 2-D inversion scheme is compatible with the structure dimensionality indicated by the data, (ii) to estimate the geoelectrical strike and then (iii) to undistort/decompose the MT data in a reference frame compatible with the retrieved strike direction. To perform these operations, several methods are nowadays available; among them it is worth mentioning those proposed by Swift (1967), Groom and Bailey (1989), Mc Neice and Jones (2001) and Weaver et al. (2000).

From geological information, it is well known that the HAV has a complex geological framework where a unique geological/geoelectrical strike cannot be defined. Ranging from the surface to the deep at least two main different strike direction can be found: the first one, $\mathrm{N} 30^{\circ} \mathrm{W}$, reflects the orientation of the intermontane basin, while the second one, $\mathrm{N} 60^{\circ} \mathrm{W}$, is related to the regional strike (Apennine chain). Being interested in the study of the deep structure of the valley, it is clear that the use of a $\mathrm{N} 45^{\circ}$ oriented reference frame represents a compromise between the surficial and deep geological strike direction with the main advantage of limiting distortion effects on the data and avoiding rotation operations.

In the present work the dimensionality analysis has been performed by means of the WAL procedure (Weaver et al., 2000) modified after Martí et al. (2004). This procedure consists of characterizing the MT response as function of seven invariants from which it is also possible to retrieve information about the dimensionality of the investigated structures. The possible dimensionality analysis outputs are 1-D, 2-D, 2-D distorted (in three different ways), 3-D and undetermined; the last case indicates the impossibility of retrieving the dimensionality from the data.

The retrieved dimensionality for the sounding is shown in Fig. 2. For short periods, the dimensionality is mainly 2D/2-D-distorted. Increasing the period, the presence of 3-D features is relevant. The undetermined status that can be observed especially from the longest periods may result from

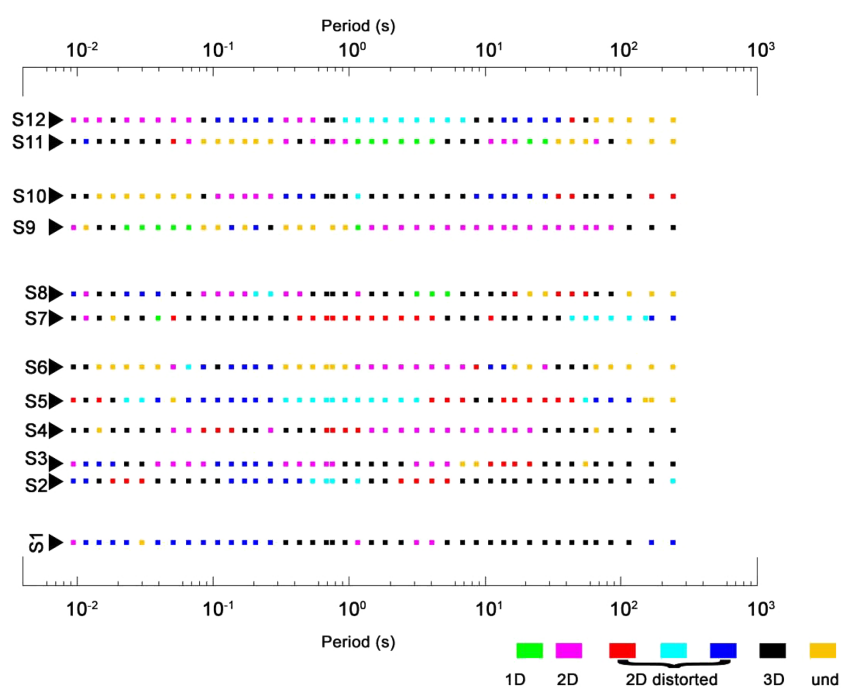

Figure 2. Dimensionality cases for all soundings at each period.

a combination of factors such as, for example, an insufficiently long time series used to obtain the MT estimate and large error bars associated with the estimates. Considering the overall results of the WAL analysis, a 2-D inversion strategy can be adopted. The geoelectrical strike direction, recovered when the output of WAL analysis is 2-D/2-D-distorted, is generally not uniform in the period or along the transect; nevertheless, a dominant $\mathrm{N} 45^{\circ}$ orientation was recovered for the long period.

The apparent resistivity and phase data (TM and TE modes) of the profile were hence inverted singularly and simultaneously by using the non-linear conjugate 2-D inversion algorithm developed by Rodi and Mackie (2001). This algorithm finds the smoothest resistivity model (Tikhonov regularization) that fits the data. A regularization parameter $\tau$ controls the trade-off between the quality of the fit and the smoothness of the model. The optimum $\tau$ value represents a compromise between the data fit and the model smoothness (see e.g. Bedrosian et al., 2004). Several inversion tests were performed using different values for the regularization parameter $\tau$.

In general when inverting only the TE mode, the magnetic $\left(H_{x}\right)$ and the electric $\left(E_{y}\right)$ components, parallel and normal to geoelectrical strike respectively, are continuous with respect to the interface and related exclusively by inductive effects; furthermore, TE mode is less affected by static shift problems. Thin conductor layers parallel to geological strike can be resolved well by the TE mode, but depth resolution is limited. Contrarily, inverting only TM mode in the 2-D approximation can obtain a better sensitivity to lateral conductivity variation and to the deep. With this in mind and considering that, as widely reported in literature (i.e. Berdichevsky and Dmitriev, 2008), TM and TE modes complement each other, we preferred to invert them simultaneously. 


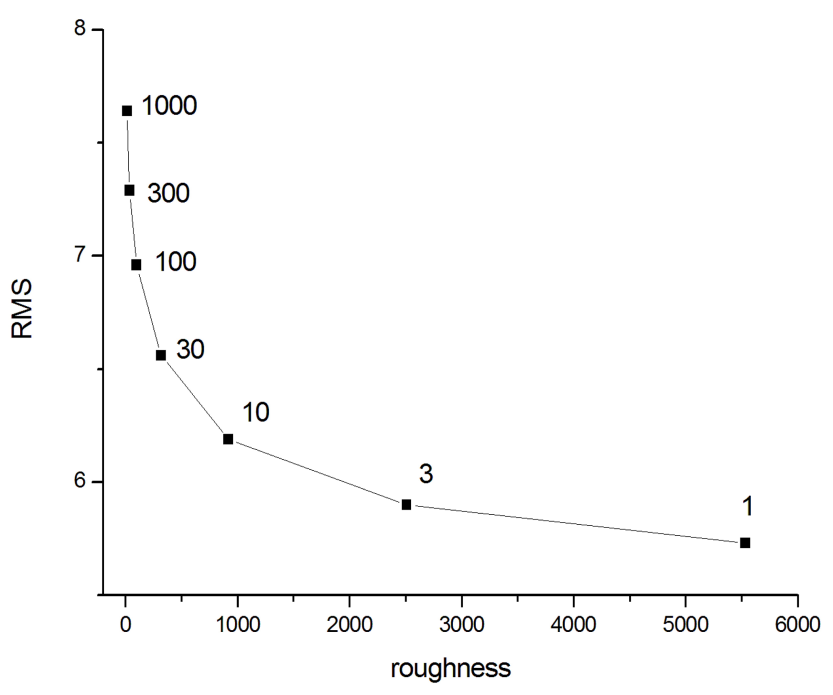

Figure 3. Normalized RMS versus roughness of the models after 30 iterations for different values of the regularization parameter $\tau$.

As a starting model, a homogeneous half-space with a resistivity of $25 \Omega \mathrm{m}$ was used. The edge effects were avoided by keeping the mesh large. To choose the optimum 2-D inversion model, a trade-off curve (i.e. $L$ curve) was estimated (Fig. 3) by plotting roughness against RMS data misfit for models with a range of smoothing parameters. The location of maximum curvature on an $L$ curve balances the opposing requirements for a spatially smooth model that honours the measured data by achieving an acceptably low data misfit (Hansen et al., 1992). Inspection of the $L$ curve (Fig. 3) reveals that the maximum curvature occurs for $\tau=10$. Analyzing the different output models for each different tau and considering the geological complexity of the investigated area and the scarcity of available data on deep geological structures, we preferred to show, on a purely precautionary measure, a final smoother model with $\tau=30$. The MT model of the area was obtained after 45 iterations with a RMS data misfit of $6.5 \%$; Fig. 4 shows the comparison between observed and calculated pseudosections, while the final model is presented in Fig. 5. Furthermore, additional information on the fit between raw data (observed data) and the model responses (calculated data) for electrical resistivity and phase for both modes are reported in Fig. S1 in the Supplement. The model resistivity values range from 10 to about $10000 \Omega \mathrm{m}$, and it is possible to recognize the presence of three main layers in depth (A, B and C), the thickness of which notably varies from SW to NE.

\section{Seismicity data}

We collected the seismicity recorded in HAV by the local seismic network owned by the company Eni (in operation since July 2001) from January 2002 to December 2012 (the data set is available at the Osservatorio Ambientale della Val d'Agri, Basilicata region, southern Italy). The waveform data set has been enriched with recordings extracted from the Italian Seismological Instrumental and Parametric Data-Base (ISIDe, http://iside.rm.ingv.it), available since 16 April 2005.

Absolute locations were performed using a non-linear global approach (NonLinLoc; Lomax et al., 2000) in the 1-D velocity model of the area proposed by Valoroso et al. (2009). Following Stabile et al. (2014a), after a first location we relocated the events using station corrections obtained in the first step, and we repeated this processing until the difference between two consecutive iterations was negligible. Most of the 1185 events are located near Pertusillo reservoir and are ascribed to the presence of the Pertusillo dam and to the wastewater injection into the Costa Molina 2 well (Valoroso et al., 2009; Stabile et al., 2014a, 2014b). Therefore, we selected those ( 22 events, see Table 1 ) within $2.5 \mathrm{~km}$ distance from the MT profile and with vertical and horizontal location errors less than $1.5 \mathrm{~km}$ that are related to natural seismicity in the HAV. Moreover, we determined the focal mechanisms (FPFIT code; Reasenberg and Oppenheimer, 1985) of events for which eight or more $P$ wave first-motion polarities with at least two compressions and two dilatations are available, and we considered only fault plane solutions with an error less than $10^{\circ}$ of the three fault plane angles. In Fig. 7 we show the projection along the MT model of seismicity and the focal mechanisms for two events (events 9 and 12, highlighted in bold in Table 1) represented with red stars. In particular, they show predominantly normal-faulting kinematics (event 9: strike1 $(2)=314^{\circ}\left(103^{\circ}\right)$, dip1 $(2)=56^{\circ}\left(38^{\circ}\right)$, rake1 (2) $=-72^{\circ}\left(-115^{\circ}\right)$; event 12: strike1 $(2)=309^{\circ}\left(107^{\circ}\right)$, dip 1 $(2)=54^{\circ}\left(38^{\circ}\right)$, rake1 $\left.(2)=-76^{\circ}\left(-108^{\circ}\right)\right)$, where numbers 1 and 2 indicate the two fault plane solutions.

\section{Results and interpretation}

The interpretation of the MT model presented in this study is based on a series of surface geology (Fig. 1), published subsurface data across the HAV (e.g. stratigraphic log of the Costa Molina 2 well in Fig. 1b), deep geological sections proposed by Mazzoli et al. (2001) and Borraccini et al. (2002) and the geophysical model shown by Dell'Aversana (2003), Valoroso et al. (2011) and Nicolai and Gambini (2007).

The MT model can be schematized as a superposition of three-piled lateral varying layers with different thickness and resistivity values (see Fig. 5).

The surficial layer (A in Fig. 5) shows a higher variability of resistivity values $(10-250 \Omega \mathrm{m}$ ) and thickness between 1.1 and about $3.5 \mathrm{~km}$. It is related to the Quaternary deposits 

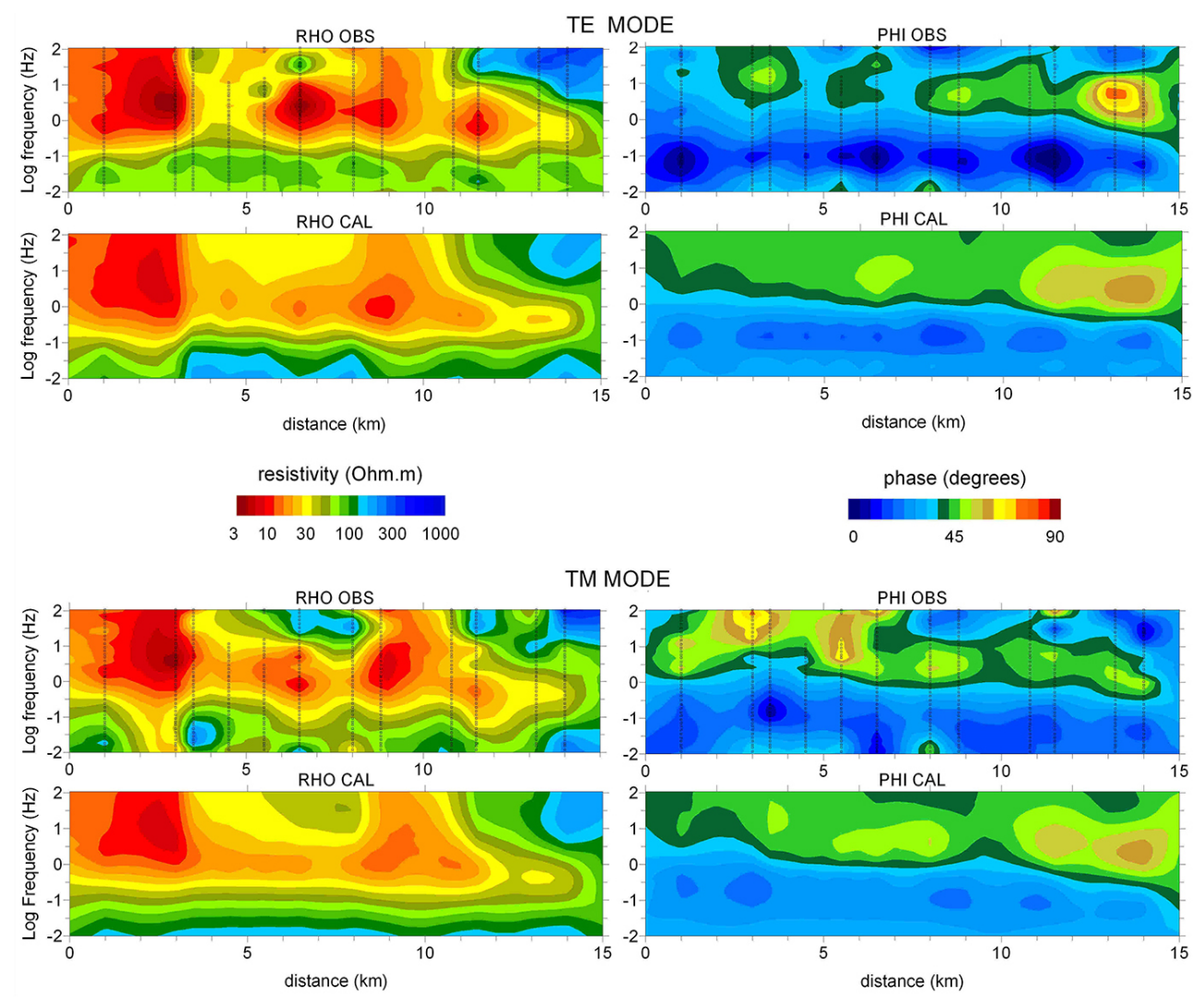

Figure 4. Apparent resistivity and phase pseudosections for the observed (OBS) and calculated (CAL) data of the MT profile reported in Fig. 1. The dot lines indicate the positions of the MT stations.

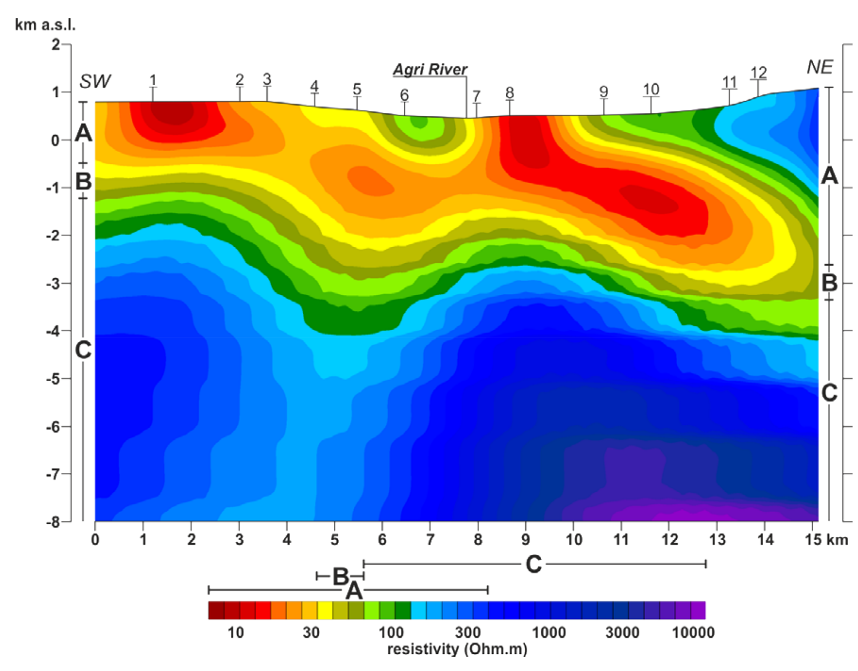

Figure 5. MT resistivity model obtained by joint inversion of TE and TM modes. A, B and $\mathrm{C}$ define the variability range of resistivity of the main features well-rendered in the model.

and to the allochthonous units (Fig. 6). In agreement with the surface geology (Fig. 1), the higher resistivity values (50$250 \Omega \mathrm{m}$ ) of the surficial layer can be attributed to the carbon- ates of the Campania Lucanian Platform, whereas the lower resistivity values $(<50 \Omega \mathrm{m})$ can be associated with the QD and to the pelagic successions of the Lagonegro units. In particular, the valley floor (between 6.5 and $10 \mathrm{~km}$ ) is marked by $\mathrm{a} \sim 1 \mathrm{~km}$ thick low-resistivity zone, which is associated with the QD.

The intermediate layer (B in Fig. 5) of medium resistivity values $(40-110 \Omega \mathrm{m})$ is associated prevalently with the mélange zone and to the Pliocene terrigenous marine deposits (Fig. 6). Such association is justified by the lack of any clear lateral discontinuity that can be attributed to the chaotic mixing of different sediments and rocks. The B layer is several hundred metres thick and locally exceeds $1 \mathrm{~km}$ in thickness just as reported in the stratigraphic log of the Costa Molina 2 well (Fig. 1b) and in the literature (Mazzoli et al., 2001).

The lower layer ( $\mathrm{C}$ in Fig. 5) of higher resistivity values $(>110 \Omega \mathrm{m})$ is related to the Mesozoic-Tertiary carbonate sequence of the Apulia Platform (Fig. 6).

The M-TM/AP boundary (dashed line in Fig. 6) is defined with a moderately high level of confidence based on the high resistivity contrast between M-TM and AP. Some uncertainty on the geometry of the LU-M boundary (dotted line in Fig. 6) arises from the fact that LU, especially in the 
Table 1. Events selected in this study. Focal mechanism has been computed for events highlighted in bold. The magnitude estimation has been retrieved from INGV catalogues, when available.

\begin{tabular}{|c|c|c|c|c|c|c|c|c|c|}
\hline \multirow[t]{2}{*}{ Event no. } & \multirow[t]{2}{*}{ Data event } & \multirow[t]{2}{*}{ Origin time } & $X$ & $Z$ & Err. $X$ & Err. $Z$ & \multirow{2}{*}{$\begin{array}{l}\text { Long } \\
\left({ }^{\circ} \mathrm{E}\right)\end{array}$} & \multirow{2}{*}{$\begin{array}{l}\text { Lat } \\
\left({ }^{\circ} \mathrm{N}\right)\end{array}$} & \multirow[t]{2}{*}{ Mag } \\
\hline & & & \multicolumn{4}{|c|}{$(\mathrm{km})$} & & & \\
\hline 1 & $31 \mathrm{Jul} 2001$ & $14: 24: 43$ & 9.07 & 10.31 & 1.3 & 1.0 & 15.8058 & 40.3843 & - \\
\hline 2 & 2 Sep 2002 & 13:08:07 & 6.07 & 3.02 & 0.5 & 0.7 & 15.8103 & 40.3288 & - \\
\hline 3 & 12 Dec 2002 & $14: 47: 47$ & 3.69 & 8.57 & 0.9 & 1.3 & 15.7985 & 40.3047 & - \\
\hline 4 & 20 Jul 2003 & $05: 22: 45$ & 12.28 & 1.37 & 1.0 & 0.6 & 15.8507 & 40.3793 & - \\
\hline 5 & 18 Dec 2003 & 01:39:13 & 6.29 & 3.06 & 0.7 & 1.0 & 15.8290 & 40.3083 & - \\
\hline 6 & 25 Apr 2004 & $10: 17: 10$ & 3.25 & 2.86 & 0.7 & 0.9 & 15.8052 & 40.2888 & - \\
\hline 7 & 25 Oct 2004 & 09:30:31 & 12.89 & 5.59 & 1.2 & 1.1 & 15.8485 & 40.3923 & - \\
\hline 8 & 18 Nov 2004 & $16: 06: 15$ & 3.51 & 3.19 & 0.8 & 1.2 & 15.7750 & 40.3322 & - \\
\hline 9 & 28 Jun 2005 & 04:35:53 & 6.70 & 9.15 & 0.7 & 0.7 & 15.8250 & 40.3203 & 2.5 \\
\hline 10 & 2 Jul 2005 & $02: 38: 12$ & 6.36 & 9.90 & 0.7 & 0.8 & 15.8235 & 40.3165 & 2 \\
\hline 11 & 2 Jul 2005 & $05: 05: 38$ & 6.55 & 9.73 & 0.7 & 0.8 & 15.8278 & 40.3142 & - \\
\hline 12 & 20 Jul 2005 & $14: 27: 22$ & 6.75 & 9.48 & 0.7 & 0.8 & 15.8272 & 40.3182 & 2.3 \\
\hline 13 & $30 \mathrm{Jul} 2005$ & $22: 14: 30$ & 6.54 & 9.98 & 0.7 & 0.7 & 15.8272 & 40.3148 & 1.4 \\
\hline 14 & 5 Nov 2005 & $09: 48: 22$ & 10.64 & 7.16 & 0.8 & 0.8 & 15.8037 & 40.4130 & 1 \\
\hline 15 & 14 Jul 2006 & $19: 31: 32$ & 5.68 & 2.94 & 0.5 & 0.7 & 15.8293 & 40.2978 & 1.1 \\
\hline 16 & 5 Oct 2008 & $14: 34: 28$ & 4.25 & 5.51 & 0.7 & 1.3 & 15.7832 & 40.3338 & 2 \\
\hline 17 & 29 Jun 2009 & $15: 58: 22$ & 12.86 & 3.02 & 0.4 & 0.6 & 15.8543 & 40.3843 & 1.4 \\
\hline 18 & 3 Dec 2009 & 08:19:11 & 3.86 & 12.21 & 1.0 & 1.2 & 15.7457 & 40.3760 & 2.4 \\
\hline 19 & 27 Jan 2010 & $06: 20: 12$ & 10.59 & 3.02 & 0.7 & 1.0 & 15.8507 & 40.3513 & 1.9 \\
\hline 20 & 23 Oct 2010 & $23: 55: 42$ & 12.25 & 9.32 & 0.8 & 0.9 & 15.8733 & 40.3495 & 1.4 \\
\hline 21 & 19 Dec 2011 & $20: 32: 05$ & 1.48 & 3.02 & 0.6 & 0.7 & 15.7773 & 40.2957 & - \\
\hline 22 & 5 Aug 2012 & $22: 37: 36$ & 9.40 & 12.01 & 0.8 & 1.1 & 15.8098 & 40.3847 & 1.8 \\
\hline
\end{tabular}

sectors where some of its formations (i.e. Galestri Formation) are located at the bottom, could have resistivity values compatible with $\mathrm{M}$.

The geometry of the TM-M/AP boundary has been compared with the one recovered by a Vp section (Fig. 4 in Valoroso et al., 2011) and by a continuous profiling highresolution magnetotelluric (HRMT, Fig. 5 in Dell'Aversana, 2003), the locations of which are shown in Fig. S2. In regard to the latter, it has to be said that a direct comparison with the model presented in this paper is not possible since in Dell'Aversana (2003) the exact location of the HRMT profile is not reported. In any case, on the basis of some indications found in another reference (Zerilli and Dell'Aversana, 2002), the trace of the profile has been hypothesized (grey band in Fig. S2). Both the HRMT model and the Vp section are characterized by the presence of two broad anticlines whose shapes are similar to the one described in the MT model presented in this paper, although it seems to be shifted, especially in Dell'Aversana's model, about $1-2 \mathrm{~km}$ NE. Such discrepancy could be attributed to an imperfect location of Dell'Aversana's model and/or to the presence of 3-D effects as also suggested by the dimensionality analysis.

From a structural viewpoint, the major features of the MT model are the sharp lateral resistivity discontinuities that involve the surficial (A) and the lower (C) layers (Fig. 6). The shallow lateral variations of resistivity intersecting the

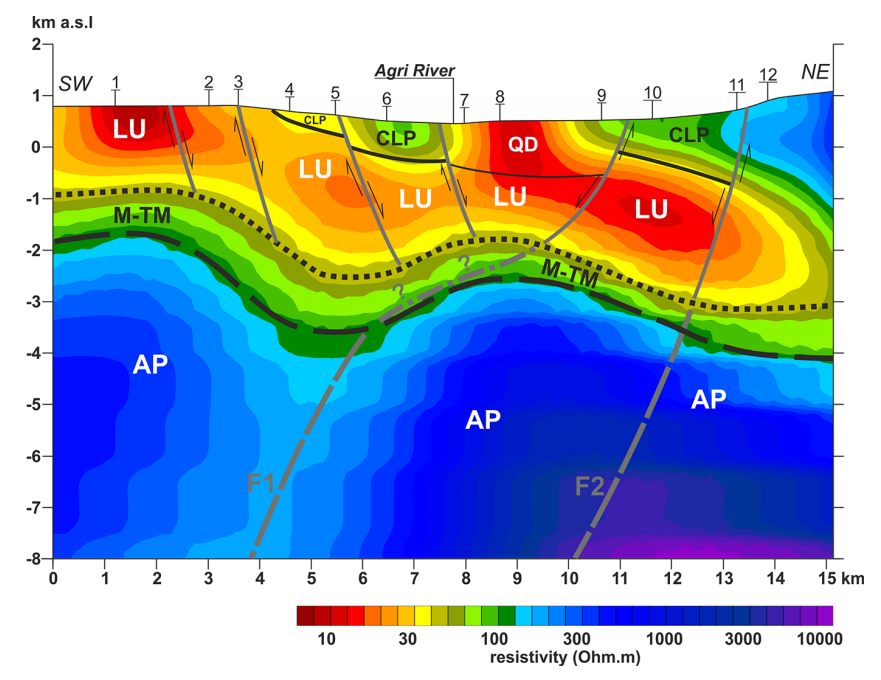

Figure 6. Schematic interpretation of the MT model. QD is Quaternary deposits; CLP is Campania Lucania Platform; LU is Lagonegro units; M-TM is mélange and terrigenous marine deposits; AP is Apulia Carbonate Platform.

layer A are interpreted as faults. The SW-dipping faults are associated with the EAFS, whereas the NE-dipping faults are attributed to the MMFS. Figure 7 shows the good agreement 


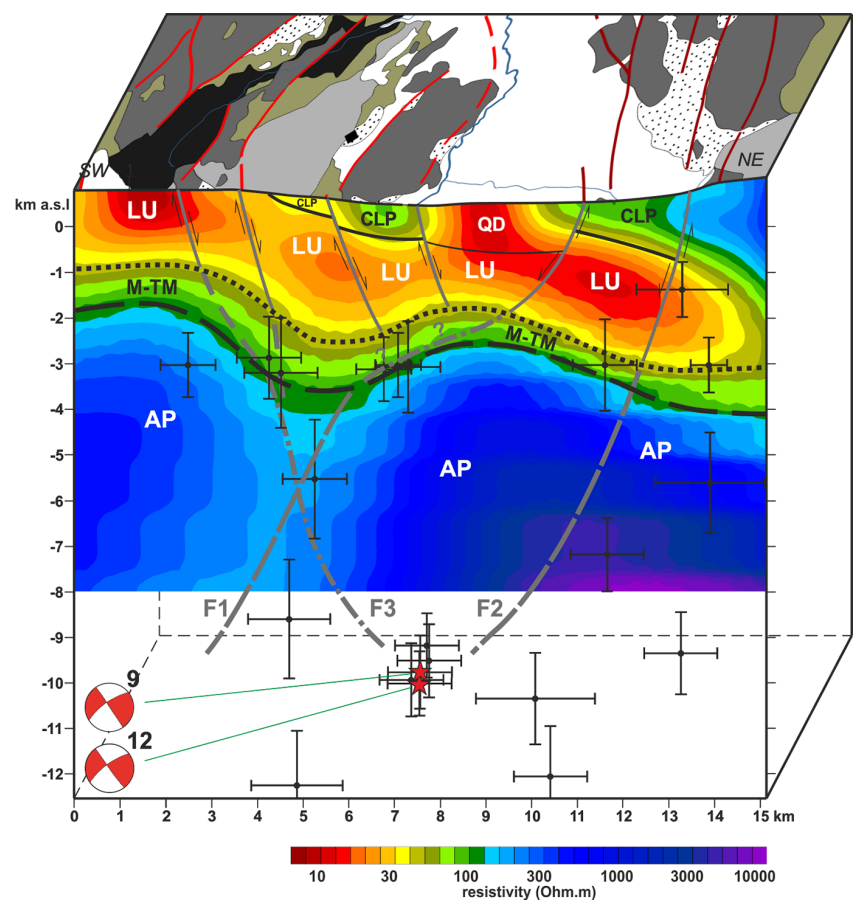

Figure 7. MT model compared with morphostructural map of the Agri Valley and projection along the MT model of seismicity. The focal mechanisms of the two events represented with red stars display normal-faulting kinematics on two possible NW-SE trending fault plane solutions, which are compatible to either F2 or F3.

between the interpreted faults and the surface geological lineaments.

At depth, in the lower layer $\mathrm{C}$, the major feature of the MT model is related to F1. Even though the significance of F1 is not fully confirmed by sensitivity tests (Campanyà et al., 2012), it is spatially coincident and compatible with the geometry of a thrust shown by Valoroso et al. (2011) after Nicolai and Gambini (2007). F1 has, thus, been interpreted as a SW-dipping fault that cuts the top of AP, just below the southwest part of the valley floor and that does not continue in the layers above (A and B).

Projection of the hypocentres along the MT model shows only a few earthquakes along the faults inferred by the MT model (i.e. F1), while it is possible to observe repeated earthquakes just below the central part of the valley floor $(\sim 7-$ $8 \mathrm{~km}$ along the section) at a depth of about $9.5 \pm 0.5 \mathrm{~km}$ below sea level (Fig. 7). Accurate focal mechanism computations display normal-faulting kinematics on two possible NW-SE trending fault plane solutions. Even if the MT model does not show clear evidences of faults geometrically compatible with these events, they could be related to two hypothetical structures related either EAFS or MMFS and named respectively F2 and F3 in Fig. 7.

\section{Discussion and conclusions}

The MT model was interpreted on the basis of the surface geology (Fig. 1) and published subsurface data across the HAV (e.g. stratigraphic log of the Costa Molina 2 well in Fig. 1b and deep geological sections proposed by Mazzoli et al., 2001; Borraccini et al., 2002; Shiner et al., 2004; Valoroso et al., 2011).

The geological setting of the HAV was schematized as a superposition of three different domains in depth (Fig. 5). The shallow one shows a higher variability of resistivity values $(10-250 \Omega \mathrm{m})$ and thickness between 1.1 and about $3.5 \mathrm{~km}$. It is related to QD and the allochthonous units. The intermediate domain of medium resistivity values (40$110 \Omega \mathrm{m})$ is associated prevalently with the mélange zone and to the Pliocene terrigenous marine deposits. The lower layer of higher resistivity values $(>90 \Omega \mathrm{m}$ ) is related to the Mesozoic-Tertiary carbonate sequence of the Apulia Platform and shows an appreciable lateral resistivity discontinuities (Fig. 6).

From a structural viewpoint, the MT model shows features related to the MMFS and EAFS in the surficial layer. At depth, in the lower layer, the major feature is related to F1, which is interpreted as a SW-dipping fault that cuts the top of AP just below the southwest part of the valley floor and does not continue in the layers above. In addition, the surface projection of this structure does not fit with the faults in the overlying allochthon. The F1 fault is also displayed in the 3-D structural model of Borraccini et al. (2002).

By a local seismic network (Eni Company), enriched with recordings extracted from the ISIDE database, we have collected 1185 located events. These events were reduced to 22 by selecting only those within $2.5 \mathrm{~km}$ distance from the MT profile and with vertical and horizontal location errors less than $1.5 \mathrm{~km}$. We show the projection along the MT model of all selected events (the focal mechanisms are available for only two events). We can observe from the Fig. 7 and Table 1 that, considering the large period of observation, the events are low magnitude $\left(M_{1} \leq 2.5\right)$ and few because of sparse seismic stations in the considered area. Nevertheless, it is possible to observe repeated earthquakes just below the central part of the valley floor $(\sim 7-8 \mathrm{~km}$ along the section) at a depth of about $9.5 \pm 0.5 \mathrm{~km}$ below sea level. Accurate focal mechanism computations of two different events display normal-faulting kinematics on two possible NW-SE trending fault plane solutions, which are compatible to either EAFS or MMFS (F2 and F3 in Fig. 7 respectively). Whereas the MT model does not support F3 presence, F2 could be a younger structure compared to $\mathrm{F} 1$, where previous intense fracturisation could permit the bearing of fluids. We conclude by pointing out the effectiveness of the inductive effects of magnetotelluric method. Results similar to the ones of the HRMT have been obtained by using less than $10 \%$ of the soundings performed for the HRMT. 


\section{The Supplement related to this article is available online at doi:10.5194/nhess-15-843-2015-supplement.}

Acknowledgements. The seismic data of the Eni network have been provided by the Osservatorio Ambientale della Val d'Agri of the Basilicata region.

Edited by: V. Lapenna

Reviewed by: A. Gabas, J. P. Makris, and one anonymous referee

\section{References}

Balasco, M., Lapenna, V., Siniscalchi, A., and Telesca, L.: Stability analysis of apparent resistivity measurement in the seismically active area of Val d'Agri (southern Italy), Nat. Hazards Earth Syst. Sci., 4, 775-781, doi:10.5194/nhess-4-775-2004, 2004.

Balasco, M., Galli, P., Giocoli, A., Gueguen, E., Lapenna, V., Perrone, A., Piscitelli, S., Rizzo, E., Romano, G., Siniscalchi, A., and Votta, M.: Deep geophysical electromagnetic section across the middle Aterno Valley: preliminary results after the April 6, 2009 l'Aquila earthquake, B. Geofis. Teor. Appl., 52, 443-455, 2011.

Barchi, M., Amato, A., Cippitelli, G., Merlini, S., and Montone, P.: Extensional tectonics and seismicity in the axial zone of the Southern Apennines, Boll. Soc. Geol. Ital., 7, 47-56, 2007.

Becken, M. and Ritter, O.: Magnetotelluric studies at the San Andreas Fault Zone: implications for the Role of Fluids, Surv. Geophys., 33, 65-105, doi:10.1007/s10712-011-9144-0, 2012.

Bedrosian, P. A.: MT+, Integrating magnetotellurics to determine earth structure, physical state, and processes, Surv. Geophys., 28, 121-167, 2007.

Bedrosian, P. A., Unsworth, M. J., Egbert, G. D., and Thurber, C. H.: Geophysical images of the creeping San Andreas Fault: implications for the role of crustal fluids in the earthquake process, Tectonophysics, 385, 137-158, 2004.

Benedetti, L., Tapponier, P., King, G. C. P., and Piccardi, L.: Surface rupture of the 1857 Southern Italian earthquake, Terra Nova, 10, 206-210, 1998.

Berdichevsky, M. and Dmitriev, V. I.: Inversion strategy, in: Models and Methods of Magnetotellurics, Springer-Verlag, Berlin, Heidelberg, 453-541, 2008.

Borraccini, F., De Donatis, M., Di Bucci, D., and Mazzoli, S.: 3D Model of the active extensional fault system of the high Agri River Valley, Southern Apennines, Italy, in: 2002 General Contributions: 2002, edited by: Jessell, M. W., J. Virtual Explor., 6, $1-8,2002$

Branno, A., Esposito, E. G. I., Maturano, A., Porfido, S., and Rinaldis, V.: Studio su base macrosismica, del terremoto della Basilicata del 16 dicembre 1857, Bollettino della Società dei Naturalisti di Napoli, 92, 249-338, 1985 (in Italian).

Burrato, P. and Valensise, G.: Rise and fall of a hypothesized seismic gap: source complexity in the 16 December 1857 , Southern Italy earthquake $\left(M_{\mathrm{W}} 7.0\right)$, B. Seismol. Soc. Am., 98, 139-148, doi:10.1785/0120070094, 2007.
Campanyà, J., Ledo, J., Queralt, P., Marcuello, A., Liesa, M., and Muñoz, J. A.: New geoelectrical characterisation of a continental collision zone in the West-Central Pyrenees: constraints from long period and broadband magnetotellurics, Earth Planet. Sc. Lett., 333-334, 112-121, doi:10.1016/j.epsl.2012.04.018, 2012.

Cello, G. and Mazzoli, S.: Apennine tectonics in Southern Italy: a review, J. Geodyn., 27, 191-211, 1999.

Cello, G., Gambini, R., Mazzoli, S., Read, A., Tondi, E., and Zucconi, V.: Fault zone characteristics and scaling properties of the Val d'Agri Fault System (Southern Apennines, Italy), J. Geodyn., 29, 293-307, 2000

Cello, G., Tondi, E., Micarelli, L., and Mattioni, L.: Active tectonics and earthquake sources in the epicentral area of the 1857 Basilicata earthquake (Southern Italy), J. Geodyn., 36, 37-50, doi:10.1016/S0264-3707(03)00037-1, 2003.

Colella, A., Lapenna, V., and Rizzo, E.: High-resolution imaging of the High Agri Valley Basin (Southern Italy) with electrical resistivity tomography, Tectonophysics, 386, 29-40, 2004.

D’Addezio, G., Karner, D. B., Burrato, P., Insinga, D., Maschio, L. Ferranti, L., and Renne, P. R.: Faulted Middle Pleistocene tephra layer in the Val d'Agri area (Southern Italy), Ann. Geophys.Italy, 49, 1029-1040, 2006.

Dell'Aversana, P.: Integration loop of "global offset" seismic, continuous profiling magnetotelluric and gravity data, First Break, 21, 32-41, doi:10.3997/1365-2397.2003019, 2003.

Diaferia, I., Loddo, M., Schiavone, D., and Siniscalchi, A.: Shallow to intermediate resistivity features of the Colfiorito Fault System inferred by DC and MT survey, Conference: Workshop on the Colfiorito Earthquake from 1997-2007 - Ten Years on Location: Roma Tre University, Rome, Italy, 8-10 October 2007, Ann. Geophys.-Italy, 51, 443-450, 2008.

Di Maio, R., Mauriello, P., Patella, D., Petrillo, Z., Piscitelli, S. and Siniscalchi, A.: Electric and electromagnetic outline of the Mount Somma-Vesuvius structural setting, J. Volcanol. Geoth Res., 82, 219-238, 1998.

Di Niro, A. and Giano, S. I.: Evoluzione geomorfologica del bordo orientale dell'alta Val d'Agri (Basilicata), Studi Geologici Camerti, 2, 207-218, 1995 (in Italian).

Di Niro, A., Giano, S. I., and Santangelo, N.: Primi dati sull'evoluzione geomorfologica e sedimentaria del bacino dell'Alta Val d'Agri (Basilicata), Studi Geologici Camerti, 1, 257-263, 1992 (in Italian).

Egbert, G. D.: Robust multiple-station magnetotelluric data processing: Geophys. J. Int., 130, 475-496, 1997.

Gabàs, A., Macau, A., Benjumea, B., Bellmunt, F., Figueras, S., and Vila, M.: Combination of geophysical methods to support urban geological mapping, Surv. Geophys., 35, 983-1002, doi:10.1007/s10712-013-9248-9, 2014.

Giano, S. I., Lapenna, V., Piscitelli, S., and Schiattarella, M.: Electrical imaging and self-potential surveys to study the geological setting of the Quaternary slope deposits in the Agri high valley (Southern Italy), Ann. Geofis., 43, 409-419, 2000a.

Giano, S. I., Maschio, L., Alessio, M., Ferranti, L., Improta, L., and Schiattarella, M.: Radiocarbon dating of active faulting in the Agri high valley, Southern Italy, J. Geodyn., 29, 371-386, $2000 \mathrm{~b}$.

Giocoli, A., Stabile, T. A., Adurno, I., Perrone, A., Gallipoli, M. R., Gueguen, E., Norelli, E., and Piscitelli, S.: Geological and geophysical characterization of the southeastern side of the High 
Agri Valley (southern Apennines, Italy), Nat. Hazards Earth Syst. Sci., 15, 315-323, doi:10.5194/nhess-15-315-2015, 2015.

Groom, R. W. and Bailey, R. C.: Decomposition of magnetotelluric impedance tensors in the presence of local three-dimensional galvanic distortion, J. Geophys. Res. 94, 1913-1925, 1989.

Hansen, P. C.: Analysis of discrete ill-posed problems by means of the L-curve, SIAM Rev., 34, 561-580, 1992.

Improta, L., Ferranti, L., De Martini, P. M., Piscitelli, S., Bruno, P. P., Burrato, P., Civico, R., Giocoli, A., Iorio, M., D’addezio, G., and Maschio, L.: Detecting young, slow-slipping active faults by geologic and multidisciplinary high-resolution geophysical investigations: a case study from the Apennine seismic belt, Italy, J. Geophys. Res., 115, B11307, doi:10.1029/2010JB000871, 2010.

Lomax, A., Virieux, J., Volant, P., and Berge, C.: Probabilistic earthquake location in $3 \mathrm{D}$ and layered models: introduction of a Metropolis-Gibbs method and comparison with linear locations, in: Advances in Seismic Event Location, edited by: Thurber, C. H. and Rabinowitz, N., Kluwer, Amsterdam, the Netherlands, 101-134, 2000.

Martí, A., Queralt, P., and Roca, E.: Geoelectric dimensionality in complex geologic areas: application to the Spanish Betic Chain, Geophys. J. Int., 157, 961-974, doi:10.1111/j.1365246X.2004.02273.x, 2004.

Maschio, L., Ferranti, L., and Burrato, P.: Active extension in Val d'Agri area, Southern Apennines, Italy: implications for the geometry of the seismogenic belt, Geophys. J. Int., 162, 591-609, doi:10.1111/j.1365-246X.2005.02597.x, 2005.

Mazzoli, S., Barkham, S., Cello, G., Gambini, R., Mattioni, L., Shiner, P., and Tondi, E.: Reconstruction of continental margin architecture deformed by the contraction of the Lagonegro Basin, southern Apennines, Italy, J. Geol. Soc. London, 158, 309-319, 2001.

McNeice, G. W. and Jones, A. G.: Multisite, multifrequency tensor decomposition of magnetotelluric data, Geophysics, 66, 158173, 2001.

Michetti, A. M., Serva, L., and Vittori, E.: ITHACA Italy Hazard from Capable Faults: a Database of Active Faults of the Italian Onshore Territory, CD-Rom and Explanatory Notes, ANPA, Rome, 2000.

Morandi, S. and Ceragioli, E.: Integrated interpretation of seismic and resistivity images across the "Val d'Agri" graben (Italy), Ann. Geophys.-Italy, 45, 259-271, doi:10.4401/ag-3510, 2002.

Nicolai, C. and Gambini, R.: Structural architecture of the Adria platform-and-basin system, Boll. Soc. Geol. Ital., Spec. Issue, 7, 21-37, 2007.

Pantosti, D. and Valensise, G.: Faulting mechanism and complexity of the November 23, 1980, Campania-Lucania earthquake, inferred from surface observation, J. Geophys. Res., 95, 1531915341, 1990.

Reasenberg, P. and Oppenheimer, D.: FPFIT, FPPLOT and FPPAGE: Fortran computer programs for calculating and displaying earthquake fault plane solutions, U.S. Geol. Surv. Open File Rep., 85-739, 262 pp., Menlo Park, California, available at: http://pubs.usgs.gov/of/1985/0739/report.pdf, last access: 30 July 2014, 1985.

Rizzo, E., Colella, A., Lapenna, V., and Piscitelli, S.: Highresolution images of the fault-controlled High Agri Valley basin (Southern Italy) with deep and shallow electrical resistivity tomographies, Phys. Chem. Earth, 29, 321-327, 2004.
Rodi, W. and Mackie, R. L.: Non linear conjugate gradient algorithm for 2D magnetotelluric inversion, Geophysics, 6, 174-187, 2001.

Scandone, P.: Studi di geologia lucana: la serie calcareo-silicomarnosa e i suoi rapporti con l'Appennino calcareo, Bollettino Società Naturalisti in Napoli, 76, 1-175, 1967 (in Italian).

Shiner, P., Beccacini, A., and Mazzoli, S.: Thin-skinned versus thick-skinned structural models for Apulian carbonate reservoirs: constraints from the Val d'Agri Fields, Mar. Petrol. Geol., 21, 805-827, doi:10.1016/j.marpetgeo.2003.11.020, 2004.

Siniscalchi, A., Tripaldi, S., Neri, M., Balasco, M., Romano, G., Ruch, J., and Schiavone, D.: Flank instability structure of Mt Etna inferred by a magnetotelluric survey, J. Geophys. Res., 117, 148-227, doi:10.1029/2011JB008657, 2012.

Stabile, T. A., Giocoli, A., Lapenna, V., Perrone, A., Piscitelli, S., and Telesca, L.: Evidences of low-magnitude continued reservoir-induced seismicity associated with the Pertusillo artificial lake (Southern Italy), B. Seismol. Soc. Am., 104, 18201828, doi:10.1785/0120130333, 2014a.

Stabile, T. A., Giocoli, A., Perrone, A., Piscitelli, S., and Lapenna, V.: Fluid injection induced seismicityreveals a NE dipping fault in the southeastern sector of the High Agri Valley (southern Italy), Geophys. Res. Lett., 41, 5847-5854, doi:10.1002/2014GL060948, 2014b.

Swift, C. M.: A Magnetotelluric Investigation of an Electrical Conductivity Anomaly in the Southwestern United States, $\mathrm{PhD}$ thesis, Mass. Inst. Technology, Cambridge, MA, USA, 211 pp., 1967.

Tank, S. B., Honkura, Y., Ogawa, Y., Oshiman, N., Tuncer, M. K., Matsushima, M., Celik, C., Tolak, E., and Isikara, A. M.: Magnetotelluric imaging of the fault rupture area of the 1999 Izmit (Turkey) earthquake, Phys. Earth Planet. In., 150, 213-225, 2005.

Valoroso, L., Improta, L., Chiaraluce, L., Di Stefano, R., Ferranti, L., Govoni, A., and Chiarabba, C.: Active faults and induced seismicity in the Val d'Agri area (southern Apennines, Italy), Geophys. J. Int. 178, 488-502, doi:10.1111/j.1365246X.2009.04166.x, 2009.

Valoroso, L., Improta, L., De Gori, P., and Chiarabba, C.: Upper crustal structure, seismicity and pore pressure variations in an extensional seismic belt through 3-D and 4-D VP and VP/VS models: the example of the Val d'Agri area (southern Italy), J. Geophys. Res., 116, B07303, doi:10.1029/2010JB007661, 2011.

Weaver, J. T., Agarwal, A. K., and Lilley, F. E. M.: Characterisation of the magnetotelluric tensor in terms of its invariants, Geophys. J. Int., 141, 321-336, doi:10.1046/j.1365246x.2000.00089.x, 2000.

Zerilli, A. and Dell'Aversana, P.: ESIT - Additional Values in Complex Structures Exploration using Alternative Geophysics, 64th EAGE conference, Florence, Italy, Extended Abstracts, E034, 27-30 May 2002. 